\title{
Maternal high-fat diet triggers metabolic syndrome disorders that are transferred to first and second offspring generations
}

\author{
Claudiane Maria Barbosa ${ }^{1}$, Vivian Paulino Figueiredo ${ }^{1}$, Maria Andréa Barbosa ${ }^{1}$, Leonardo \\ Máximo Cardoso ${ }^{1,2}$ and Andréia Carvalho Alzamora ${ }^{1,2 *}$ \\ ${ }^{1}$ Núcleo de Pesquisa em Ciências Biológicas-Programa de Pós-Graduação em Ciências Biológicas, Universidade Federal de \\ Ouro Preto, 35400-O0 Ouro Preto, MG, Brazil \\ ${ }^{2}$ Departamento de Ciências Biológicas, Instituto de Ciências Exatas e Biológicas, 35400-OO Ouro Preto, MG, Brazil
}

(Submitted 6 May 2019 - Final revision received 7 October 2019 - Accepted 8 October 2019)

\section{Abstract}

A high-fat $(\mathrm{H})$ diet increases metabolic disorders in offspring. However, there is great variability in the literature regarding the time of exposure, composition of the $\mathrm{H}$ diets offered to the genitors and/or offspring and parameters evaluated. Here, we investigated the effect of a $\mathrm{H}$ diet subjected to the genitors on different cardio-metabolic parameters on first (F1)- and second (F2)-generation offspring. Female Fischer rats, during mating, gestation and breast-feeding, were subjected to the H diet (G0HF) or control (G0CF) diets. Part of F1 offspring becomes G1 genitors for generating the F2 offspring. After weaning, F1 and F2 rats consumed only the C diet. Nutritional, biometric, biochemical and haemodynamic parameters were evaluated. GOHF genitors had a reduction in food intake but energy intake was similar to the control group. Compared with the control group, the F1H and F2H offspring presented increased plasma leptin, insulin and fasting glucose levels, dietary intake, energy intake, adiposity index, mean arterial pressure, sympathetic drive evidenced by the hexamethonium and insulin resistance. Our data showed that only during mating, gestation and breast-feeding, maternal $\mathrm{H}$ diet induced cardio-metabolic disorders characteristic of human metabolic syndrome that were transferred to both females and males of F1 and F2 offspring, even if they were fed control diet after weaning. This process probably occurs due to the disturbance in mechanisms related to leptin that increases energy intake in $\mathrm{F} 1 \mathrm{H}$ and $\mathrm{F} 2 \mathrm{H}$ offspring. The present data reinforce the importance of balanced diet during pregnancy and breast-feeding for the health of the F1 and F2 offspring.

\section{Key words: Metabolic syndrome: Offspring: High-fat diet: Leptin: Energy intake}

Studies of weaned rats fed a high-fat $(\mathrm{H})$ diet have shown disorders characteristic of the human metabolic syndrome $(\mathrm{MetS})^{(1,2)}$. Additionally, poor diet of the genitors can influence the health of the offspring ${ }^{(3)}$. An increase in white adipose tissues ${ }^{(4-6)}$ is prevalent among the disturbances observed in offspring, which are induced by a maternal $\mathrm{H}$ diet. Deposits of white adipose tissues produce leptin that acts on the brain inducing reduction in food intake and increased activity of the sympathetic nervous system $^{(7,8)}$. Leptin-binding sites in the brain regions are also important in cardiovascular control, suggesting that the influence of leptin on cardiovascular functions ${ }^{(9)}$. Insulin resistance (IR) may also occur due to increased white adipose tissues, leading to hyperinsulinaemia ${ }^{(10)}$. Arterial hypertension has a genetic origin or environmental factors such as sedentary lifestyle and/or unbalanced diets ${ }^{(11)}$. Hypertension involves hyperactivity of the sympathetic nervous system with dysfunction of the baroreflex control that is crucial for short-term control of the mean arterial pressure $(\mathrm{MAP})^{(11)}$.

Studies from the literature have subjected the genitors to a $\mathrm{H}$ diet for different periods of time, in which female rats received the $\mathrm{H}$ diet shortly after weaning or variable weeks before mating. The present study aims to investigate the characteristic disorders of the MetS induced by a $\mathrm{H}$ diet subjected to the genitors (G0) only during mating, gestation and breast-feeding, which in turn led to different cardiometabolic parameters in both females and males of F1 and F2 offspring, even if those offspring after weaning were fed only the control diet (C).

Abbreviations: C diet, control diet; F1, first generation; F2, second generation; GJ, fasting glucose; H diet, high-fat diet; HOMA- $\beta$, homeostasis evaluation of the functional capacity of $\beta$ cells; HOMA-IR, homeostatic model assessment of insulin resistance; HR, heart rate; MAP, mean arterial pressure.

* Corresponding author: Andréia Carvalho Alzamora, email andreiaalzamora@ufop.edu.br 
Table 1. Composition and energy content of diets*

\begin{tabular}{lcc}
\hline Ingredients (g/kg) & Control (AIN-93M) & High-fat diet \\
\hline Maize starch & $620 \cdot 70$ & - \\
Sucrose & 100.00 & - \\
Fructose & - & $34 \cdot 2$ \\
Casein & 140.00 & 180.50 \\
Condensed milk & - & 316.00 \\
Soyabean oil & 40.00 & - \\
Lard & - & 370.00 \\
Fibre (cellulose) & 50.00 & 50.00 \\
Wheat bran & - & - \\
Mineral mix (AIN-93G-MX) & - & 35.00 \\
Mineral mix (AIN-93M-MX) & 35.00 & - \\
Vitamin mix (AIN-93G-VX) & 10.00 & 10.00 \\
DL-Methionine & 1.80 & 3.00 \\
Choline chloride & 2.50 & 2.50 \\
Macronutrients (\% by weight) & & \\
Protein & 14.00 & 20.26 \\
Carbohydrate & 72.07 & 20.68 \\
Fat & 4.00 & 39.53 \\
Macronutrients (\% energy) & & \\
Protein & 14.72 & 15.60 \\
Carbohydrate & 75.82 & 15.92 \\
Fat & 9.46 & 68.48 \\
$\quad$ Saturated & 15.20 & 28.09 \\
$\quad$ Monounsaturated & 23.30 & 28.47 \\
$\quad$ Polyunsaturated & 60.00 & 8.86 \\
kcal/g & 3.80 & 5.20 \\
kJ/g & 15.91 & 21.77 \\
\hline AIN Amen & & \\
\hline
\end{tabular}

AIN, American Institute of Nutrition.

* Composition of diets $(\mathrm{g} / \mathrm{kg})$ consumed by rats. The percentage of energy was calculated based on the energy provided by each macronutrient as follows: carbohydrates $4 \mathrm{kcal} / \mathrm{g}$, $4 \mathrm{kcal}$ proteins $/ \mathrm{g}$ and lipids $9 \mathrm{kcal} / \mathrm{g}$. The percentage of polyunsaturated,

monounsaturated and saturated fats was calculated according to the total amount of lipids (g) supplied in each diet. To convert energy in kcal to $\mathrm{kJ}$, multiply by 4.184.

\section{Materials and methods}

\section{Animals}

Fischer rats were kept in individual cages and they were exposed to $12 \mathrm{~h}$ dark-12 h light (Animal Science Center - UFOP). All procedures were performed in accordance with the Guidelines for Ethical Care of Experimental Animals and approved by the Animal Ethics Committee of the Federal University of OuroPreto (Protocol 2016/49).

\section{Diets}

Rats subjected to the control (C) diet (American Institute of Nutrition (AIN)-93M) consisted of $14.7 \%$ proteins, $75.8 \%$ carbohydrates and $9.5 \%$ lipids with an energy value of $15.91 \mathrm{~kJ} /$ $\mathrm{g}$, and the $\mathrm{H}$ diet ( $37 \%$ of lard; Pragsoluções Ltda.) consisted of $15.58 \%$ proteins, $16.0 \%$ carbohydrates and $68.42 \%$ total lipids (37\% from lard) having an energy value of $21.77 \mathrm{~kJ} / \mathrm{g}$, according to de Castro $(2013)^{(12)}$ (Table 1).

\section{Experimental protocol}

Primiparous female (220 (sem 10) g; $n$ 20) and male (290 (SEM 10) g; $n$ 20) non-consanguineous rats (90-d-old) (G0) were interbreed for $10 \mathrm{~d}$. Rats were kept in plastic cage $(30 \times 21 \times$ $19 \mathrm{~cm}$ ) with free access to food and water. Females, in individual cages, continued to receive the $\mathrm{C}$ or $\mathrm{H}$ diet during gestation (21 d) and breast-feeding ( $28 \mathrm{~d}$ ). Eight pups per genitor were maintained to ensure homogenous growth. After weaning, litter males and females (first-generation (F1) offspring) were relocated to collective cages (4-5 animals/cage) and received only the $\mathrm{C}$ diet until $90 \mathrm{~d}$ of age. A group of 90-d-old F1-generation male and female rats who are the offspring of genitors fed the $\mathrm{C}$ or $\mathrm{H}$ diet were separated for interbreed to obtain the second (F2) generation. The F2 generation was fed only the $\mathrm{C}$ diet for $90 \mathrm{~d}$. The experimental groups (four $\mathrm{C}$ diets and four $\mathrm{H}$ diets) are described in Fig. 1.

\section{Evaluation of food, energy and water intake and coefficient of food efficiency}

Twice a week in the morning, diet was weighed and the volume of water consumed was measured. Food intake and water intake per animal were calculated. Energy intake was calculated by the formula: energy intake $=$ food intake $(\mathrm{g}) \times$ (energy value of the diet in $\mathrm{kcal})^{(4)}$. (To convert energy in kcal to kJ, multiply by $4 \cdot 184$.)

Coefficient of food efficiency was calculated by the relation between the body mass $(\mathrm{g})$ gain and energy intake (kcal), that is, the coefficient of food efficiency $(\mathrm{kcal} / \mathrm{g})=$ (body mass gain (g)/energy intake $(\mathrm{kcal}))^{(13)}$.

\section{Indirect and direct cardiovascular evaluations of mean arterial pressure}

Indirect MAP levels were measured using plethysmography (LE 5160-R; Panlab) only in the genitor male rats after they were interbred.

Direct evaluations were performed after $48 \mathrm{~h}$ by artery and femoral vein cannulation under anaesthesia, with a mixture of ketamine and xylazine (80 and $10 \mathrm{mg} / \mathrm{kg}$, respectively, intraperitoneally) (Syntec). Pulsatile MAP was monitored by an MLT1199 pressure transducer coupled to an arterial pressure signal amplifier (ML221 Bridge Amp; AD Instruments). Online data were obtained for MAP and heart rate (HR) from the pulsatile arterial pressure waves. All variables were continuously recorded using a PowerLab digital acquisition system (PowerLab 4/30; AD Instruments) with a 1000-Hz sampling rate and a $20-\mathrm{mV}$ digitising window.

\section{Sensitivity evaluation of the baroreflex bradycardia}

Baroreflex bradycardia was determined by recording the reflex HR changes in response to transient increases in MAP caused by repeated bolus injections of graded doses of phenylephrine (0.5-40 $\mu$ g, intravenously (i.v.); Sigma Chemical Co.) in conscious freely moving rats. The HR was converted to pulse interval (mseg) by the formula: $60000 / \mathrm{HR}$. For each animal, a best-fit regression line was drawn based on MAP and HR changes obtained due to the different doses of phenylephrine. Slope of regression line was used as an index of baroreflex sensitivity (baroreflex gain), as described elsewhere ${ }^{(14)}$.

\section{Influence of sympathetic blockade on mean arterial pressure and heart rate}

MAP was recorded before and $15 \mathrm{~min}$ after injecting the sympathetic ganglionic blocker, hexamethonium $(20 \mathrm{mg} / \mathrm{kg}$ iv; Sigma Chemical Co.). 


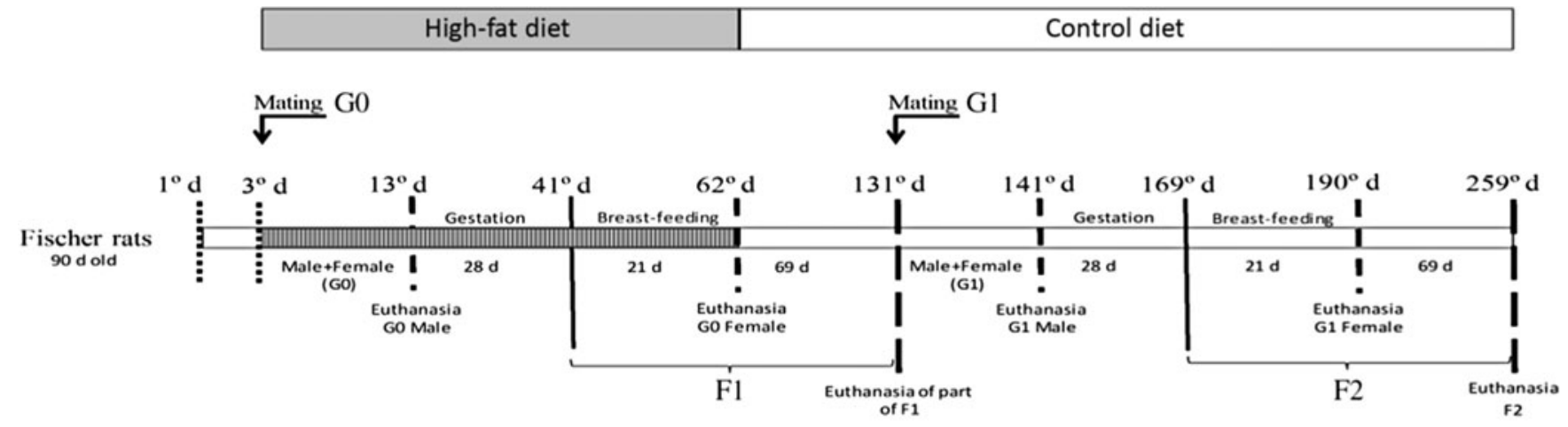

Experimental groups:

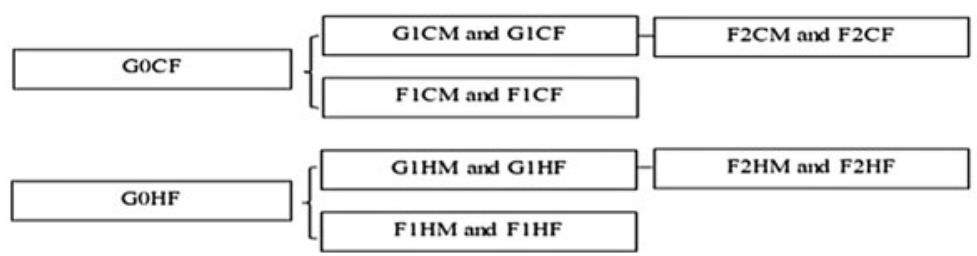

Fig. 1. Experimental design. GOCM and GOHM groups: male genitors subjected to control $(\mathrm{C})$ or high-fat $(\mathrm{H})$ diet, respectively, in the mating period (10 d); GoCF and GOHF groups: female genitors subjected to $\mathrm{C}$ and $\mathrm{H}$ diets, respectively, in the mating, gestation and breast-feeding period (59 d); F1CM and F1HM groups: male offspring from genitors who consumed the $\mathrm{C}$ and $\mathrm{H}$ diets, respectively. $\mathrm{F} 1 \mathrm{CF}$ and $\mathrm{F} 1 \mathrm{HF}$ groups: female offspring born from genitors who consumed $\mathrm{C}$ or $\mathrm{H}$ diet, respectively. All offspring (F1C or F1H) were fed only the $\mathrm{C}$ diet for $90 \mathrm{~d}$ immediately after weaning; $\mathrm{G} 1 \mathrm{CM}$ and $\mathrm{G} 1 \mathrm{HM}$ groups: $\mathrm{F} 1$ males whose the genitors (G0) consumed $\mathrm{C}$ and $\mathrm{H}$ diets, respectively, became the parent of $\mathrm{F} 2$ offspring and were only subjected to the $\mathrm{C}$ diet; $\mathrm{G} 1 \mathrm{CF}$ and $\mathrm{G} 1 \mathrm{HF}$ groups: $\mathrm{F} 1$ females whose the genitors (G0) consumed $\mathrm{C}$ and $\mathrm{H}$ diets, respectively, became the genitor of the $\mathrm{F} 2$ offspring and were subjected only to the $\mathrm{C}$ diet; $\mathrm{F} 2 \mathrm{CM}$ and $\mathrm{F} 2 \mathrm{HM}$ groups: male offspring from genitors (G1). F2CF and F2HF groups: female offspring from genitors (G1) who consumed the $\mathrm{C}$ and $\mathrm{H}$ diets, respectively. All offspring (F2C or F2H) were fed only the $\mathrm{C}$ diet for 90 d immediately after weaning.

\section{Evaluation of biometric parameters}

Naso-anal length was used to calculate the Lee index: (body mass gain $(\mathrm{g}) 1 / 3 /$ naso-anal length $(\mathrm{cm}) \times 1000)$. Adiposity index was calculated using the formula (absolute mass $(\mathrm{g})$ of the inguinal fat deposits + retroperitoneal + epididymal/body weight of the rat $(\mathrm{g}) \times 100)$. The homeostatic model assessment of insulin resistance $($ HOMA-IR $)=(\mathrm{IJ} \times \mathrm{GJ}) / 22 \cdot 5$. HOMA- $\beta$, homeostasis evaluation of the functional capacity of $\beta$ cells $=(20 \times \mathrm{IJ}) /(\mathrm{GJ}-3.5)$, where $\mathrm{IJ}=$ fasting insulin in $\mu \mathrm{U} /$ $\mathrm{ml}$ and $\mathrm{GJ}=$ fasting glucose in $\mathrm{mmol} / \mathrm{l}^{(15)}$.

\section{Biochemical analysis}

After 12-h fasting, the blood samples $(3 \mathrm{ml})$ were collected in heparinised tubes and centrifuged $\left(4000 \mathrm{rpm}, 4^{\circ} \mathrm{C}, 6 \mathrm{~min}\right)$. Plasma samples were stored at $-80^{\circ} \mathrm{C}$ for biochemical analysis. Total cholesterol, TAG and glucose levels were determined using individual commercial kits (Labtest), according to the instructions provided by the manufacturer. Insulin and leptin levels were determined by Elisa sandwich immunoassay method using the ultra-sensitive rat insulin Elisa kit (Crystal Chem).

\section{Statistical analysis}

Data were analysed using the Kolmogorov-Smirnov test to evaluate normality and followed the normal standard distribution. The results were statistically evaluated by the Student's $t$ test and expressed as mean values with their standard errors. Statistical analyses were performed by the GraphPad Prism software (version 6.00). Differences between pairs of means were considered significant at $P<0 \cdot 05$. Sample size, Cohen's $d$ effect size and statistical power (power calculator for independent $t$ test or paired $t$ test; https://www.dssresearch.com/ resources/calculators/statistical-power-calculator-average) were calculated (effect size calculators by Dr Lee A. Becker, University of Colorado, Colorado Springs; https://www.uccs. edu/lbecker); $d$ and $r$ were calculated using means and standard deviations to analyse data and identify statistically relevant differences in the energy intake, dietary coefficient, MAP levels, baroreflex bradycardia sensitivity, reduction in MAP variation induced by the sympathetic ganglion blocker hexamethonium, adiposity index, leptin, fasting glucose (GJ), total cholesterol and TAG levels. The thresholds for small, medium and large effects were $0 \cdot 20,0.50$ and 0.80 , respectively. Complete sample statistical analyses are shown in the online Supplementary material.

\section{Results}

\section{GOHF and G1HF female genitors}

The G0HF showed decreased food intake (13 (sem 2.1) g/d, $n$ 6), water intake (8.8 (sem 3.9) $\mathrm{ml} / \mathrm{d}, n 6$ ), increased body mass gain (287 (sem 5.84) g, $n$ 6) and coefficient of food efficiency (0.045 (sem 0.006) kcal/g per d, $n$ 6) compared with G0CF rats

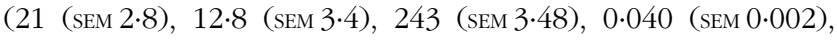
$n$ 6, respectively), with no change in energy intake (69.4 (SEм 2.75), 78.7 (SEM 3.72) kcal/d, $n$ 6, respectively) (Fig. 2(a)). The G1HF daughters of G0HF fed only the C diet showed increased body mass gain (256 (sem 6.03), $n$ 5) compared with 

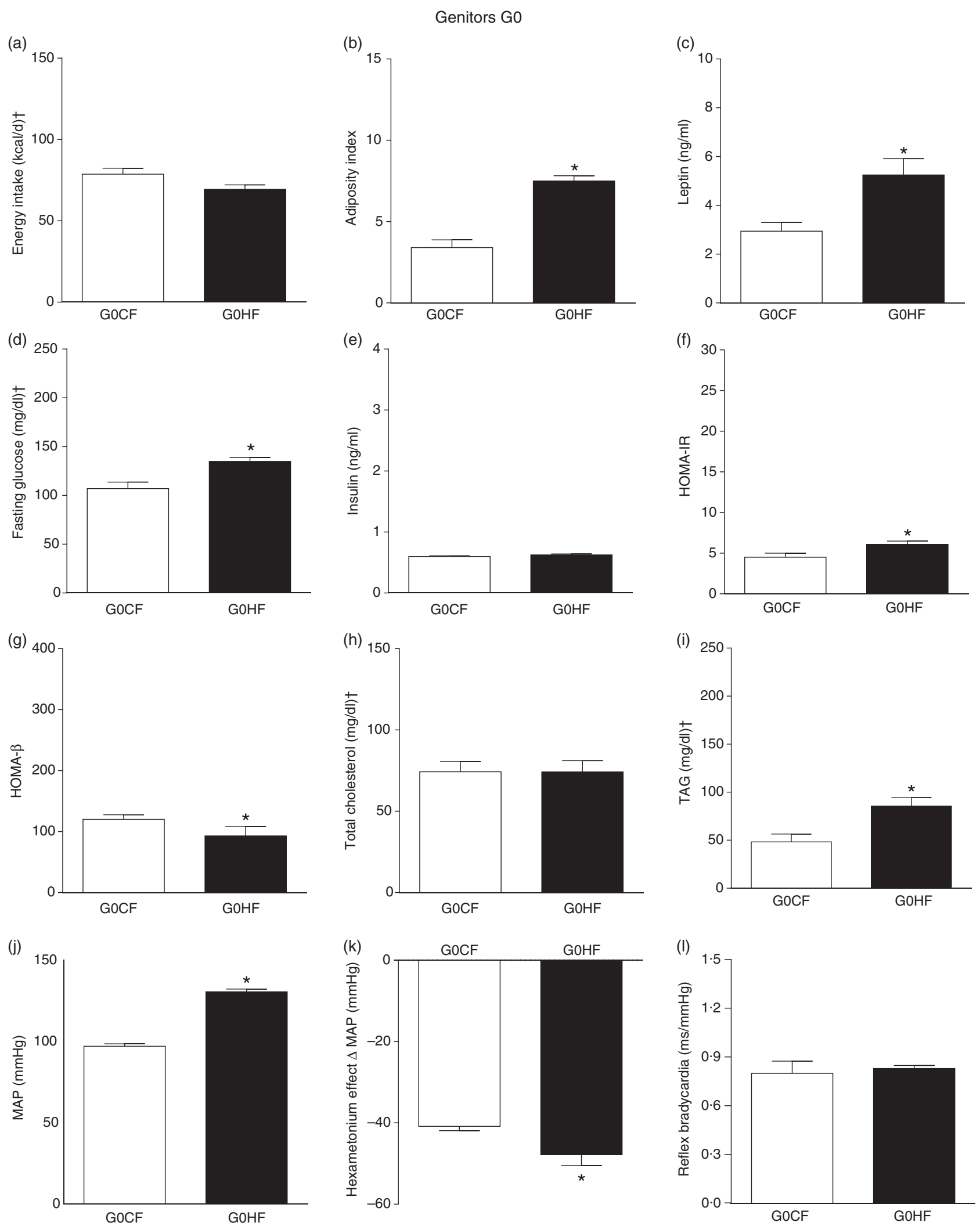

Fig. 2. Biometrical, biochemical and haemodynamic parameters of female Go genitors subjected to high-fat (H; GOHF) or control (C; GoCF) diet during mating, gestation and breast-feeding (59 d). (a) Energy intake (kcal/d). (b) Adiposity index. (c) Plasma levels of leptin ( $\mathrm{ng} / \mathrm{ml}$ ). (d) Fasting glucose (mg/dl). (e) Plasma levels of insulin ( $\mathrm{ng} / \mathrm{ml}$ ). (f) Homeostatic model assessment of insulin resistance (HOMA-IR). (g) Homeostasis evaluation of the functional capacity of $\beta$ cells (HOMA- $\beta$ ). (h) Plasma total cholesterol levels ( $\mathrm{mg} / \mathrm{dl})$. (i) Plasma total TAG levels (mg/dl). (j) Mean arterial pressure (MAP, $\mathrm{mmHg}$ ). (k) Variation in MAP induced by the hexamethonium ganglionic blocker $(\Delta \mathrm{mmHg})$. (l) Sensitivity of reflex bradycardia ( $\mathrm{ms} / \mathrm{mmHg}) .{ }^{*} P<0.05$ compared with the G0CF group (Student's $t$ test). $†$ To convert energy in kcal to $\mathrm{kJ}$, multiply by 4.184 . To convert glucose in $\mathrm{mg} / \mathrm{dl}$ to $\mathrm{mmol} / \mathrm{l}$, multiply by 0.0555 . To convert cholesterol in $\mathrm{mg} / \mathrm{dl}$ to $\mathrm{mmol} / \mathrm{l}$, multiply by 0.0259 . To convert TAG in $\mathrm{mg} / \mathrm{dl}$ to $\mathrm{mmol} / \mathrm{l}$, multiply by 0.0113 . 

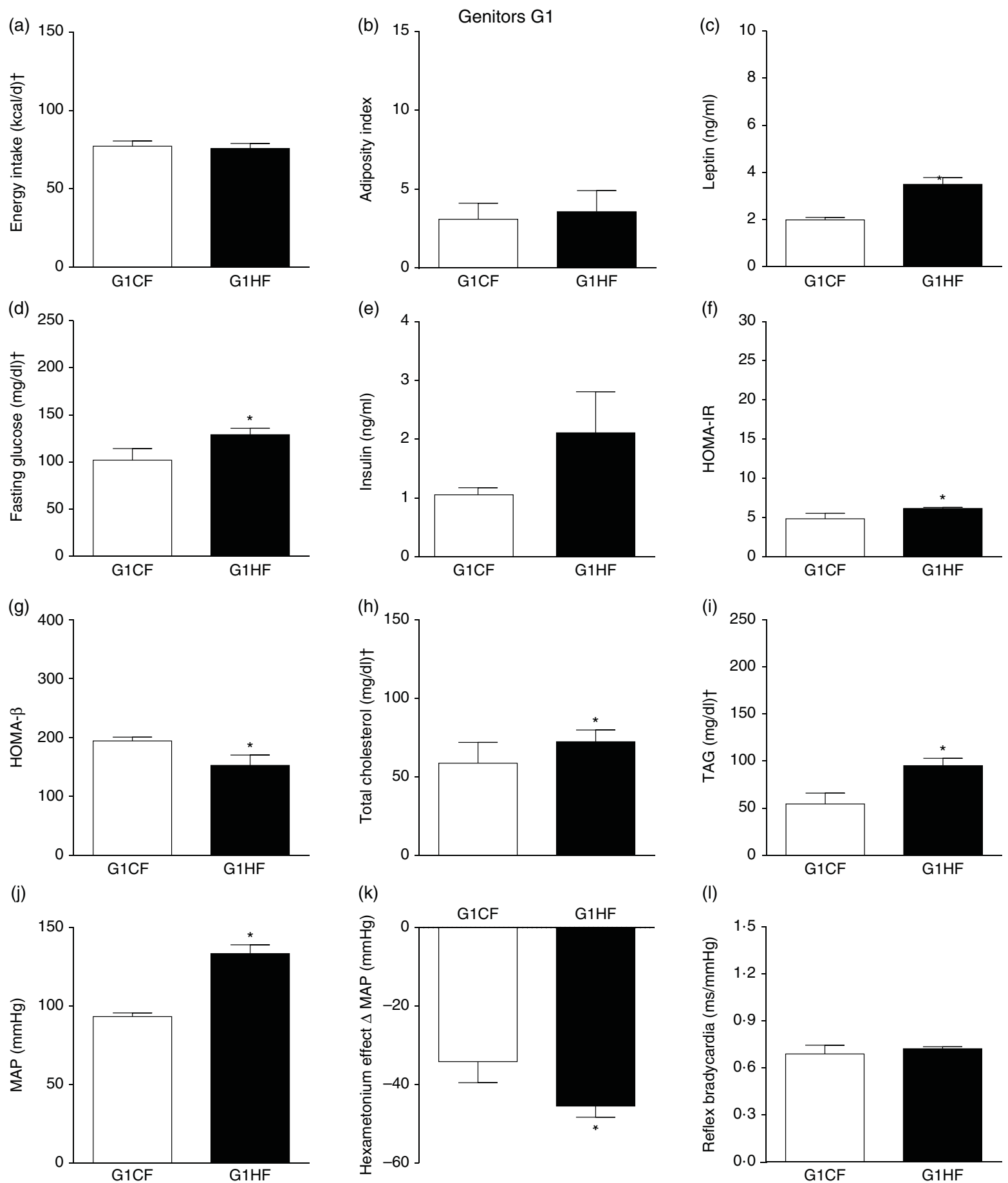

Fig. 3. Biometrical, biochemical and haemodynamic parameters of female $\mathrm{G} 1$ genitors whose parents were fed high-fat (H, G1HF) or control (C, G1CF) diet, who consumed only the $\mathrm{C}$ diet. (a) Energy intake (kcal/d). (b) Adiposity index. (c) Plasma levels of leptin ( $\mathrm{ng} / \mathrm{ml}$ ). (d) Fasting glucose (mg/dl). (e) Plasma levels of insulin $(\mathrm{ng} / \mathrm{ml})$. (f) Homeostatic model assessment of insulin resistance (HOMA-IR). (g) Homeostasis evaluation of the functional capacity of $\beta$ cells (HOMA- $\beta$ ). (h) Plasma total cholesterol levels (mg/dl). (i) Plasma total TAG levels (mg/dl). (j) Mean arterial pressure (MAP, mmHg). (k) Variation in MAP induced by the hexamethonium ganglionic blocker $\left(\Delta \mathrm{mmHg}\right.$ ). (I) Sensitivity of reflex bradycardia (ms/mmHg). ${ }^{*} P<0.05$ compared with the G1CF group (Student's $t$ test). $\dagger$ To convert energy in kcal to $\mathrm{kJ}$, multiply by 4.184 . To convert glucose in $\mathrm{mg} / \mathrm{dl}$ to $\mathrm{mmol} / \mathrm{l}$, multiply by 0.0555 . To convert cholesterol in $\mathrm{mg} / \mathrm{dl}$ to $\mathrm{mmol} / \mathrm{l}$, multiply by 0.0259 . To convert TAG in $\mathrm{mg} / \mathrm{dl}$ to $\mathrm{mmol} / \mathrm{l}$, multiply by 0.0113 .

the G1CF rats (216 (sem 6.14), $n$ 7), without any changes in energy intake (Fig. 3(a)), water intake (29.1 (sEm 4.3) G1CF, 32.6 (sem 3.9) G1HF, $n$ 6) and coefficient of food efficiency (0.031 (sEM 0.001) G1CF, 0.037 (sEM 0.003) G1HF). In addition, the G0HF and G1HF showed increased blood levels of leptin, GJ, TAG, HOMA-IR and MAP and reduction in MAP variation induced by hexamethonium, the sympathetic ganglion blocker when compared with their corresponding G0CF and G1CF 
groups. GOHF genitors showed an increase in the adiposity index and reduction in HOMA- $\beta$, with no change in blood levels of total cholesterol compared with G0CF group. However, the G1HF genitor showed increased total cholesterol and HOMA-IR, with no change in adiposity index, blood levels of insulin and HOMA- $\beta$ compared with the G1CF group. There was no difference in the sensitivity of reflex bradycardia in G0HF and G1HF animals compared with their respective controls (Figs. 2 and 3).

\section{GOHM and G1HM male genitors}

Male rats were fed with the $\mathrm{H}$ diet (GOHM) only during mating $(10 \mathrm{~d})$ showed an increase in the body mass gain (335 (sem 7.7) g, $n$ 7), basal MAP (126 (sem 4) mmHg, $n$ 7) and HR (408 (sEM 15) beats/min, $n$ 7) in comparison with the G0CM group (310 (SEM 4.6), 112 (SEM 4), 371 (SEM 7), $n$ 8, respectively). There was no significant difference in the adiposity index, GJ, total cholesterol and TAG between the G0CM and GOHM groups (data not shown).

The G1HM genitors that were fed only the $\mathrm{C}$ diet, whose genitors were GOHF and G0HM, had an increase in GJ (96.5 (SEM 6.8) $\mathrm{mg} / \mathrm{dl}, n$ 7) and TAG levels (207 (sem 14.7) $\mathrm{mg} / \mathrm{dl}$, $n 7$ ) in comparison with their G1CM group (82.6 (SEM 2.41), 152 (sем 3.6), $n$ 6, respectively). No significant difference was observed in the adiposity index, body mass gain, total cholesterol, basal MAP and HR among groups G1CM and G1HM (data not shown). (To convert $\mathrm{GJ}$ in $\mathrm{mg} / \mathrm{dl}$ to $\mathrm{mmol} / \mathrm{l}$, multiply by 0.0555 . To convert TAG in $\mathrm{mg} / \mathrm{dl}$ to $\mathrm{mmol} / \mathrm{l}$, multiply by 0.0113 .)

\section{F1HF and F2HF female offspring}

The F1HF and F2HF showed an increase in food intake (24 (SEM 5.4) g/d, $n$ 9, F1HF and 25 (SEM 5.5), $n$ 15, F2HF), water intake $(23$ (SEM 6.8) $\mathrm{ml} / \mathrm{d}, n$ 9, F1HF and 26.8 (SEM 7.4), $n$ 15, F2HF), coefficient of food efficiency $(0.072$ (sem 0.003$) \mathrm{kcal} / \mathrm{g}$ per $\mathrm{d}, n 5$, F1HF and 0.079 (sEM 0.011), $n 7, \mathrm{~F} 2 \mathrm{HF}$ ), body mass gain (218 (sEm 5.14) g, $n$ 9, F1HF and 209.1 (sem 2.07), $n$ 15, F2HF) compared with the F1CF (14 (sEm 2.9), $n$ 18; 18 (SEM 6.1), $n$ 18; 0.061 (sem 0.002), $n$ 6; 192 (SEM 3.9), $n 15$, respectively) and F2CF (14.7 (SEM 3.0), $n 12 ; 19 \cdot 5$ (SEM 10.3), $n 12 ; 0.047$ (SEM 0.001), $n 7 ; 187$ (SEM 1.82), $n 12$, respectively). In addition, the F1HF and F2HF rats presented an increase in energy intake, adiposity index, plasma leptin levels, fasting plasma glucose, HOMA-IR and reduction in HOMA- $\beta$; and increase in plasma levels of total cholesterol and TAG and MAP and a greater reduction in MAP variation induced by hexamethonium, the sympathetic ganglion blocker compared with the F1CF and F2CF, respectively (Figs. 4 and 5). However, no difference was observed in the sensitivity of reflex bradycardia in F1HF, F2HF, F1CF and F2CF groups (Figs. 4 and 5).

\section{F1HM and F2HM male offspring}

F1HM and F2HM showed increased food intake $(32 \cdot 3$ (SEM 4.4) g/d, $n$ 14, F1HM and 33 (SEM 5.5), $n$ 12, F2HM), water intake $(24(\operatorname{sem} 4 \cdot 3) \mathrm{ml} / \mathrm{d}, n 14 ; \mathrm{F} 1 \mathrm{HM}$ and 26 (SEM 4.1), $n$ 12, F2HM), coefficient of food efficiency (0.095 (sem 0.004) kcal/g per d, $n$ 5, F1HM and 0.098 (SEM 0.003), $n$ 6, F2HM) and body mass gain (341 (SEM 1.3) g, $n$ 14, F1HM and 336 (SEM 2.6), $n$ 12; F2HM) compared with the F1CM (18 (SEM 4.9), $n$ 16; 12 (sem 5.5), $n$ 16; 0.081 (sem 0.002), $n$ 6; 299 (SEM 0.70), $n$ 16, respectively) and F2CM (19 (SEM 5.0), $n$ 11; 18 (SEM 3.7), $n$ 11; 0.078 (sem 0.003), $n$ 6; 266 (sem 0.47), $n$ 11, respectively). In addition, the F1HM and F2HM rats demonstrated increased energy intake, adiposity index, plasma leptin levels, GJ levels, insulin, HOMA-IR and reduction in HOMA- $\beta$; and increase in plasma TAG levels, MAP and a greater reduction in MAP variation induced by hexamethonium, the sympathetic ganglion blocker compared with the F1CM and F2CM, respectively (Figs. 6 and 7). Only F1HM offspring showed an increase in plasma levels of total cholesterol (Fig. 7). No difference was observed in the sensitivity of reflex bradycardia among the F1CM, F1HM, F2CM and F2HM groups (Figs. 6 and 7).

\section{Discussion}

In summary, our data show that the genitors subjected to the $\mathrm{H}$ diet demonstrated disorders characteristic of the MetS, which in turn were transferred to F1 and F2 offspring, even when they were fed the $\mathrm{C}$ diet after weaning. Interestingly, rats fed the $\mathrm{H}$ diet (GOHF) adjusted energy consumption through lower food intake. However, although the $\mathrm{F} 1 \mathrm{H}$ and $\mathrm{F} 2 \mathrm{H}$ offspring were fed only the $\mathrm{C}$ diet after weaning, these rats showed increased diet and energy intake. In spite of this difference in energy intake observed between genitors and offspring, all these animals showed several cardio-metabolic disturbances characteristic of the MetS. Our hypothesis explaining the transference of these cardio-metabolic disturbances to the $\mathrm{F} 1 \mathrm{H}$ and $\mathrm{F} 2 \mathrm{H}$ offspring, respectively, due to the altered uterine environment and germ cells of $\mathrm{F} 1 \mathrm{H}$ induced by the progenitor's $\mathrm{H}$ diet is due to the injury in the metabolic intracellular signalling pathways $^{(16-18)}$.

Food intake, energy expenditure and body mass gain are regulated by leptin that acts as a signalling factor between adipose tissue and the central nervous system ${ }^{(6,19)}$. Studies from the literature ${ }^{(20-23)}$ and from our previous data ${ }^{(24)}$ subjecting rats to a $\mathrm{H}$ diet showed that rats have the ability to balance food intake and energy intake. In fact, literature data using mice ${ }^{(25)}$ fed a $\mathrm{H}$ diet showed higher energy efficiency with similar consumption of energy intake and hyperleptinaemia, suggesting alteration in hypothalamic modulation of leptin signalling. Similarly, the present study shows that the genitors fed the $\mathrm{H}$ diet consumed a smaller amount of the $\mathrm{H}$ diet but displayed energy intake similar to those fed the C diet. Despite this similarity in energy intake, these $\mathrm{GOH}$ genitors showed greater coefficient of food efficiency, adiposity index and high plasma levels of leptin, meaning that the $\mathrm{GOH}$ genitors were more efficient in converting the same amount of energy into a larger body mass gain, evidencing the importance of SFA representing the main change in $\mathrm{H}$ diet composition used in the present study.

Additionally, studies $^{(4,26)}$ showed that females subjected to a $\mathrm{H}$ diet after weaning until breast-feeding induce hypothalamic resistance to leptin in $\mathrm{F} 1$ offspring, leading to an increase in body 

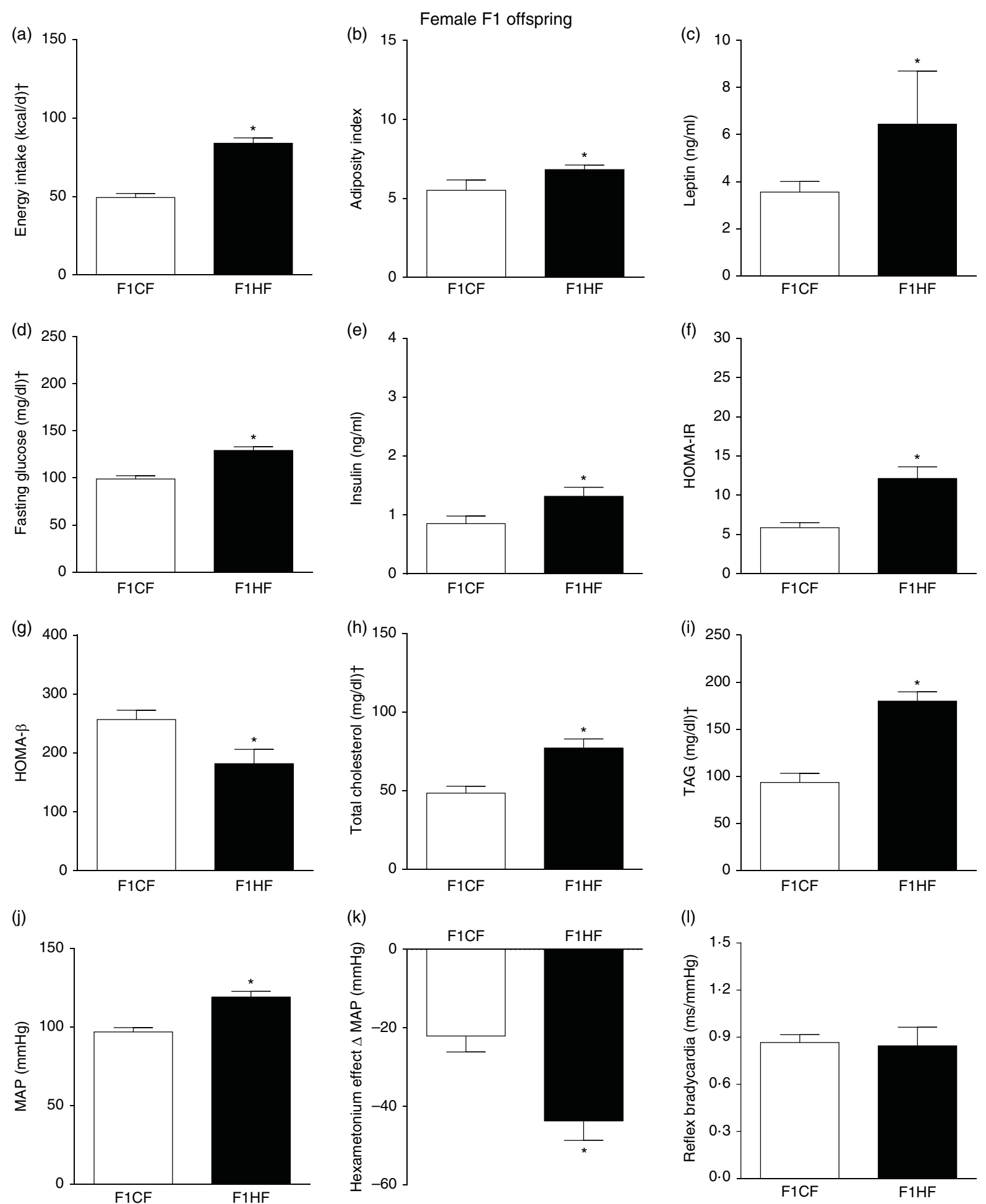

Fig. 4. Biometrical, biochemical and haemodynamic parameters of female $F 1$ offspring whose parents were fed high-fat (H, F1HF) or control (C, F1CF) diet, who consumed only the $\mathrm{C}$ diet. (a) Energy intake (kcal/d). (b) Adiposity index. (c) Plasma levels of leptin ( $\mathrm{ng} / \mathrm{ml})$. (d) Fasting glucose (mg/dl). (e) Plasma levels of insulin $(\mathrm{ng} / \mathrm{ml}$ ). (f) Homeostatic model assessment of insulin resistance (HOMA-IR). (g) Homeostasis evaluation of the functional capacity of $\beta$ cells (HOMA- $\beta$ ). (h) Plasma total cholesterol levels (mg/dl). (i) Plasma total TAG levels (mg/dl). (j) Mean arterial pressure (MAP, mmHg). (k) Variation in MAP induced by the hexamethonium ganglionic blocker $(\Delta \mathrm{mmHg})$. (I) Sensitivity of reflex bradycardia $(\mathrm{ms} / \mathrm{mmHg}) .{ }^{*} P<0.05$ compared with the F1CF group (Student's $t$ test). $\dagger$ To convert energy in kcal to $\mathrm{kJ}$, multiply by 4.184 . To convert glucose in $\mathrm{mg} / \mathrm{dl}$ to $\mathrm{mmol} / \mathrm{l}$, multiply by 0.0555 . To convert cholesterol in $\mathrm{mg} / \mathrm{dl}$ to $\mathrm{mmol} / \mathrm{l}$, multiply by 0.0259 . To convert TAG in $\mathrm{mg} / \mathrm{dl}$ to $\mathrm{mmol} / \mathrm{l}$, multiply by 0.0113 . 

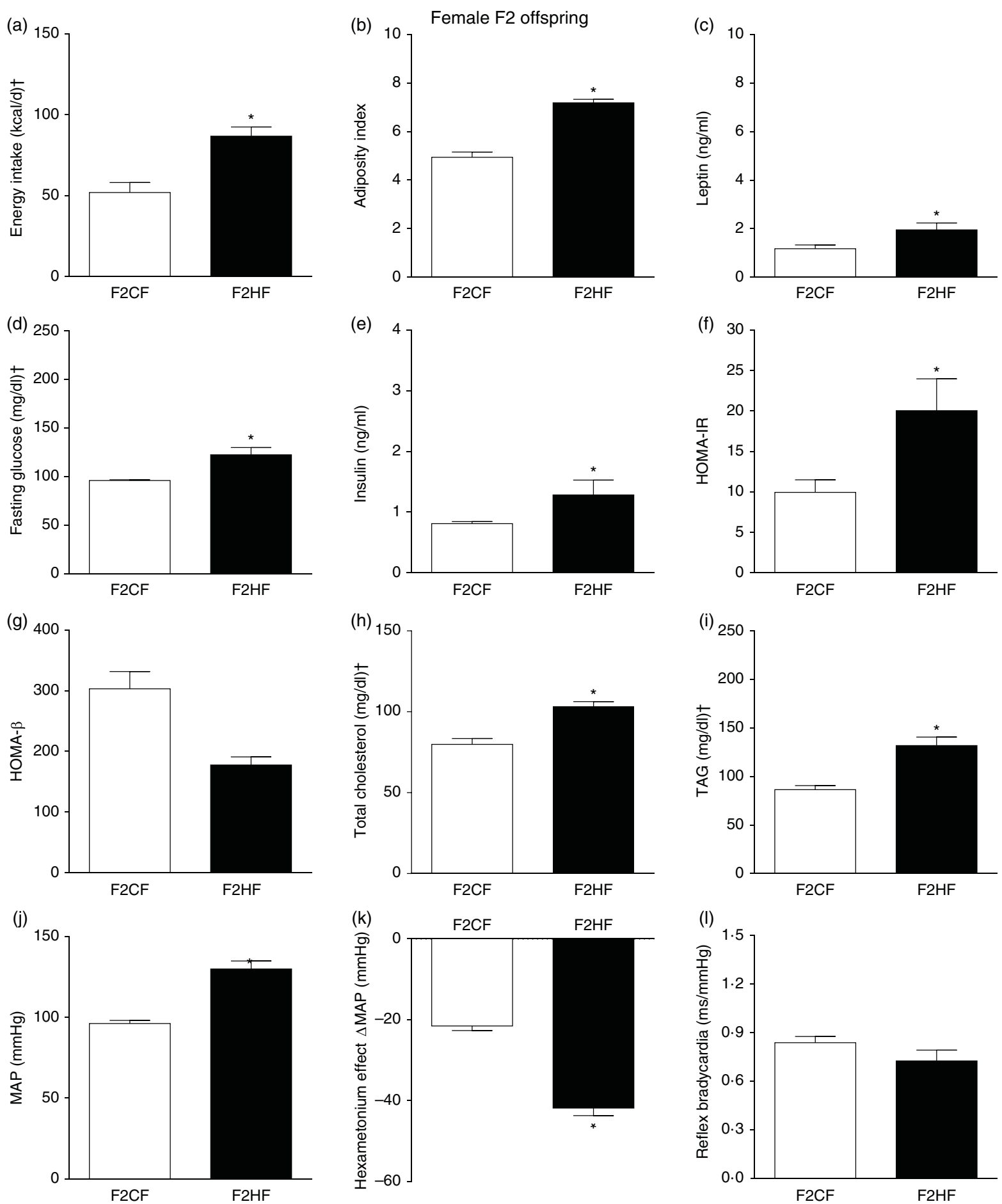

Fig. 5. Biometrical, biochemical and haemodynamic parameters of female $\mathrm{F} 2$ offspring, whose genitors were fed high-fat (H, F2HF) or control (C, F2CF) diet, who ate only the $\mathrm{C}$ diet. (a) Energy intake (kcal/d). (b) Adiposity index. (c) Plasma levels of leptin ( $\mathrm{ng} / \mathrm{ml})$. (d) Fasting glucose (mg/dl). (e) Plasma levels of insulin $(\mathrm{ng} / \mathrm{ml})$. (f) Homeostatic model assessment of insulin resistance (HOMA-IR). (g) Homeostasis evaluation of the functional capacity of $\beta$ cells (HOMA- $\beta$ ). (h) Plasma total cholesterol levels (mg/dl). (i) Plasma total TAG levels (mg/dl). (j) Mean arterial pressure (MAP, $\mathrm{mmHg}$ ). (k) Variation in MAP induced by the hexamethonium ganglionic blocker $(\Delta \mathrm{mmHg})$. (I) Sensitivity of reflex bradycardia $(\mathrm{ms} / \mathrm{mmHg}){ }^{*} P<0.05$ compared with the F2CF group (Student's $t$ test). $\dagger$ To convert energy in kcal to $\mathrm{kJ}$, multiply by 4.184 . To convert glucose in $\mathrm{mg} / \mathrm{dl}$ to $\mathrm{mmol} / \mathrm{l}$, multiply by 0.0555 . To convert cholesterol in $\mathrm{mg} / \mathrm{dl}$ to $\mathrm{mmol} / \mathrm{l}$, multiply by 0.0259 . To convert TAG in $\mathrm{mg} / \mathrm{dl}$ to $\mathrm{mmol} / \mathrm{l}$, multiply by 0.0113 .

mass in adulthood. In our present data, although the genitors were fed the $\mathrm{H}$ diet only during mating, gestation and breastfeeding, it seems to agree with these studies in the literature ${ }^{(4,26)}$ related to the $\mathrm{F} 1 \mathrm{H}$ offspring and extends this observation to $\mathrm{F} 2 \mathrm{H}$ offspring. Indeed, although the progenitors showed a similarity in the energy intake, they showed alteration in uterine and sanguine environment in gestation and breast-feeding, as increase in adiposity index, high plasma levels of leptin and 

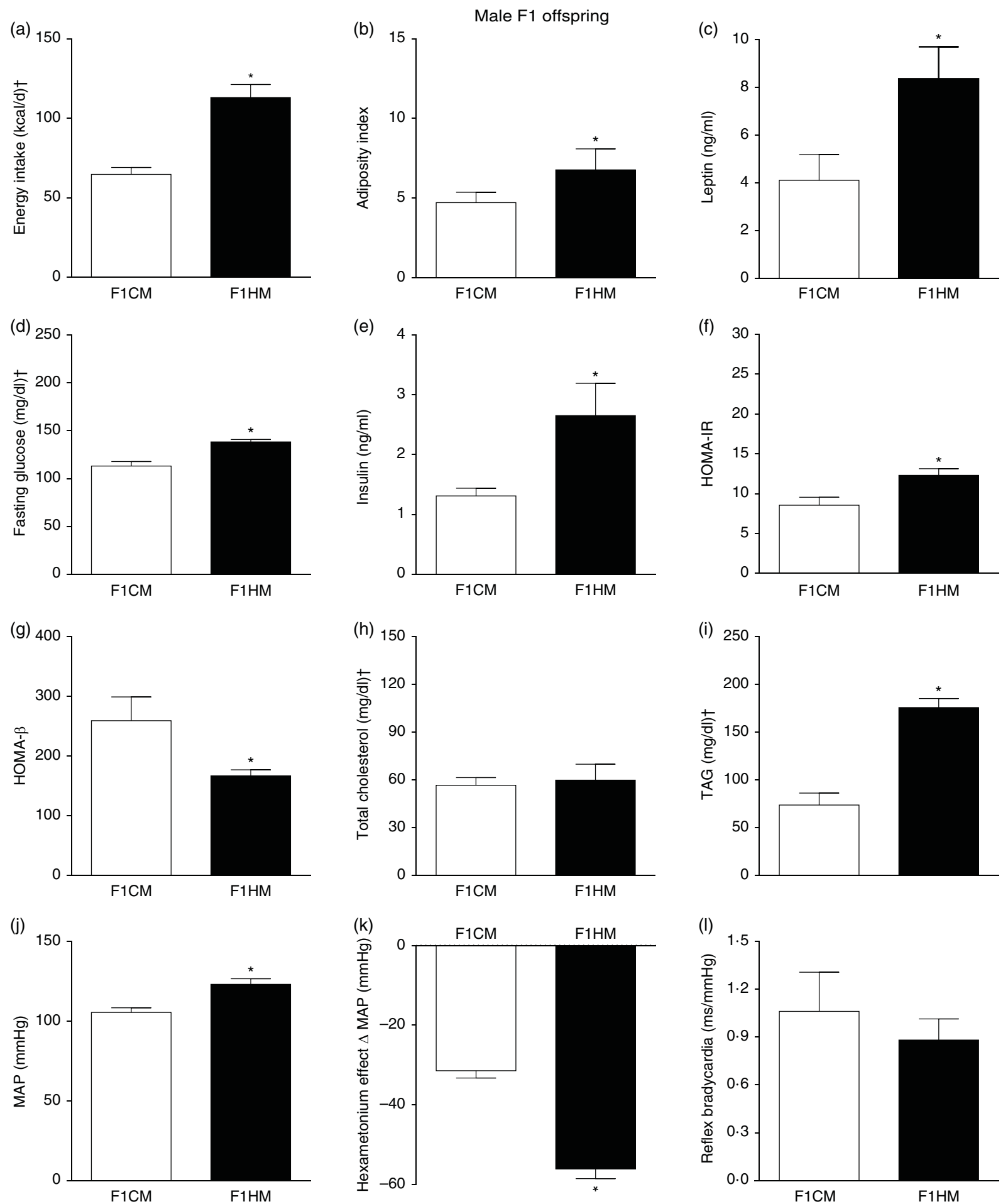

Fig. 6. Biometrical, biochemical and haemodynamic parameters of male $\mathrm{F} 1$ offspring, whose parents were fed high-fat (H, F1HM) or control (C, F1CM) diet, who consumed only the $\mathrm{C}$ diet. (a) Energy intake (kcal/d). (b) Adiposity index. (c) Plasma levels of leptin ( $\mathrm{ng} / \mathrm{ml})$. (d) Fasting glucose (mg/dl). (e) Plasma levels of insulin (ng/ml). (f) Homeostatic model assessment of insulin resistance (HOMA-IR). (g) Homeostasis evaluation of the functional capacity of $\beta$ cells (HOMA- $\beta$ ). (h) Plasma total cholesterol levels (mg/dl). (i) Plasma total TAG levels (mg/dl). (j) Mean arterial pressure (MAP, mmHg). (k) Variation in MAP induced by the hexamethonium ganglionic blocker $(\Delta \mathrm{mmHg})$. (I) Sensitivity of reflex bradycardia $(\mathrm{ms} / \mathrm{mmHg}) .{ }^{*} P<0.05$ compared with the F1CM group (Student's $t$ test). $\dagger$ To convert energy in kcal to kJ, multiply by 4.184 . To convert glucose in $\mathrm{mg} / \mathrm{dl}$ to $\mathrm{mmol} / \mathrm{l}$, multiply by 0.0555 . To convert cholesterol in $\mathrm{mg} / \mathrm{dl}$ to $\mathrm{mmol} / \mathrm{l}$, multiply by 0.0259 . To convert TAG in $\mathrm{mg} / \mathrm{dl}$ to $\mathrm{mmol} / \mathrm{l}$, multiply by 0.0113 . 

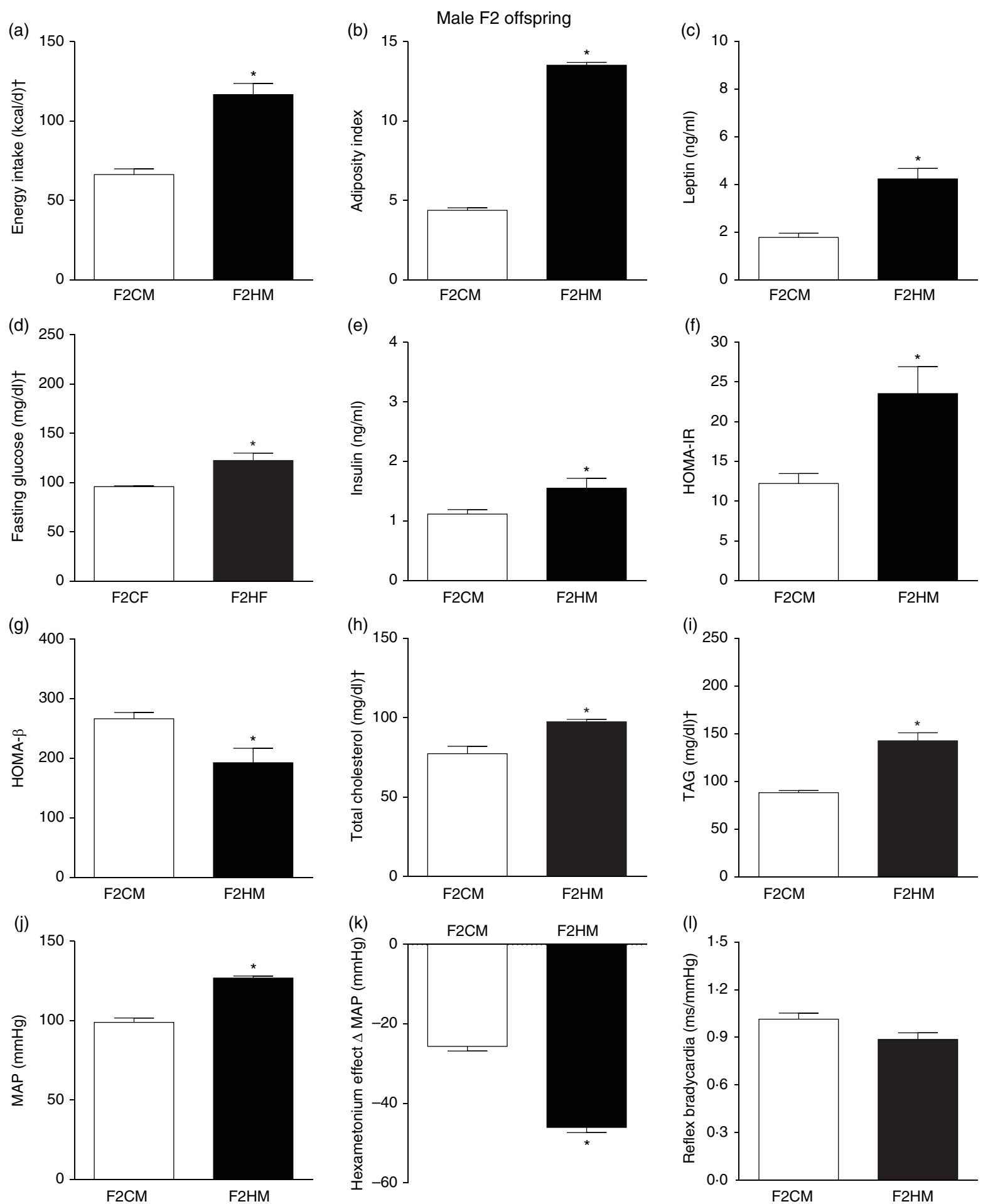

Fig. 7. Biometrical, biochemical and haemodynamic parameters of male F2 offspring, whose genitors were fed high-fat (H, F2HM) or control (C, F2CM) diet, who ate only the $\mathrm{C}$ diet. (a) Energy intake (kcal/d). (b) Adiposity index. (c) Plasma levels of leptin ( $\mathrm{ng} / \mathrm{ml})$. (d) Fasting glucose (mg/dl). (e) Plasma levels of insulin (ng/ml). (f) Homeostasis evaluation of insulin resistance (HOMA-IR). (g) Homeostasis evaluation of the functional capacity of $\beta$ cells (HOMA- $\beta$ ). (h) Plasma total cholesterol levels (mg/dl). (i) Plasma total TAG levels ( $\mathrm{mg} / \mathrm{dl})$. (j) Mean arterial pressure (MAP, $\mathrm{mmHg}$ ). (k) Variation in MAP induced by the hexamethonium ganglionic blocker $(\Delta \mathrm{mmHg})$. (I) Sensitivity of reflex bradycardia ( $\mathrm{ms} / \mathrm{mmHg}) .{ }^{*} P<0.05$ compared with the F2CM group (Student's $t$ test). $\dagger$ To convert energy in $\mathrm{kcal}$ to $\mathrm{kJ}$, multiply by 4.184 . To convert glucose in $\mathrm{mg} / \mathrm{dl}$ to $\mathrm{mmol} / \mathrm{l}$, multiply by 0.0555 . To convert cholesterol in $\mathrm{mg} / \mathrm{dl}$ to $\mathrm{mmol} / \mathrm{l}$, multiply by 0.0259 . To convert TAG in $\mathrm{mg} / \mathrm{dl}$ to $\mathrm{mmol} / \mathrm{l}$, multiply by 0.0113 .

GJ could contribute to the increase in leptin levels in $\mathrm{F} 1 \mathrm{H}$ and F2H rats. The high plasma levels of leptin in $\mathrm{F} 1 \mathrm{H}$ and $\mathrm{F} 2 \mathrm{H}$ rats probably have induced higher energy intake and consequently triggered other disorders. In fact, the evaluation of the correlation between the plasma level of leptin of G0H progenitor and $\mathrm{F} 2 \mathrm{H}$ offspring showed a positive correlation 
with the plasma level of leptin $(r 0.8363$, effect size $=-1 \cdot 29$; statistical power $=0.99)$ and energy intake $(r$ 0.9797, effect size $=-3 \cdot 12 ;$ statistical power $=1$ ).

The literature already presents studies showing the effect of $\mathrm{H}$ diet on $\mathrm{F} 1 \mathrm{H}$ offspring ${ }^{(27-31)}$ and few studies on $\mathrm{F} 2 \mathrm{H}$ offspring ${ }^{(29,32)}$. However, these studies presented a great variability in experimental protocols such as the percentage of energy from $\mathrm{H}$ diet, the period of time when the $\mathrm{H}$ diet was subjected to the genitors or even to offspring and also the parameters evaluated. This large variability in these studies makes it difficult to understand the importance of the $\mathrm{H}$ diet subjected to the progenitors in the health of offspring. In the present study, our goal was to highlight the nutritional importance of the female genitor only during the mating, gestation and breast-feeding period in the cardiometabolic health of F1 and F2 offspring.

Studies using rats genitors ${ }^{(17,27,31)}$ and mice ${ }^{(28-30)}$ that were subjected to a $\mathrm{H}$ diet for a long time after weaning until breast-feeding exhibited increased body mass, plasma levels of leptin, total cholesterol, glucose, insulin and HOMA-IR, which are transmitted to $\mathrm{F}^{(27-31)}$, while high body mass gain, impaired glucose tolerance and lower insulin levels were transmitted to $\mathrm{F} 2^{(29,32)}$. According to and extending these observations, data from the present study showed that both male and female $\mathrm{F} 1 \mathrm{H}$ and $\mathrm{F} 2 \mathrm{H}$ offspring showed increase in plasma levels of leptin leading to increased food and energy intake, adiposity index and consequently body mass gain ${ }^{(4,28,33)}$, and IR evidenced by the HOMA- $\beta^{(34)}$ reduction and increased HOMA-IR, plasma levels of glucose, TAG and total cholesterol ${ }^{(7)}$.

Additionally, cardiovascular alterations induced by the $\mathrm{H}$ diet in the genitors were transferred to both male and female $\mathrm{F} 1 \mathrm{H}$ and $\mathrm{F} 2 \mathrm{H}$ offspring. The $\mathrm{F} 1 \mathrm{H}$ and $\mathrm{F} 2 \mathrm{H}$ showed an increase in basal MAP, without any change in HR or bradycardia sensitivity. The evaluation of the sympathetic contribution to the basal MAP levels using the ganglion blocker hexamethonium showed a greater drop in MAP in the GOHM genitors and in female and male $\mathrm{F} 1 \mathrm{H}$ and $\mathrm{F} 2 \mathrm{H}$ offspring, suggesting that an increase in MAP is due, at least in part, to the increase in sympathetic drive to the cardiovascular system ${ }^{(35-37)}$. The increase in basal MAP in $\mathrm{F} 1 \mathrm{H}$ and $\mathrm{F} 2 \mathrm{H}$ offspring are consistent with the previous studies where female genitors were fed $\mathrm{H}$ diet for long-term, including before pregnancy until lactation ${ }^{(38-40)}$. According to Zhang et al. ${ }^{(41)}$, female rats fed a $\mathrm{H}$ diet for 2 weeks before pregnancy until lactation showed no changes in basal MAP and blunted tachycardia baroreflex sensitivity in the F1H offspring. The difference in the basal MAP observed between our present study and Zhang et al. study ${ }^{(41)}$ may be due to the differential age of the $\mathrm{F} 1 \mathrm{H}$ offspring. In addition, the baroreflex presents two components, the tachycardic that represents sympathetic activity and the bradycardic that represents parasympathetic activity ${ }^{(42,43)}$. In the Zhang et $a l .{ }^{(41)}$ study, only reflex tachycardia was evaluated, whereas in the present study only reflex bradycardia was evaluated. The sympathetic dysfunction was evidenced in our present study and suggests a dysfunction in the reflex tachycardia according to data from Zhang et al. ${ }^{(41)}$. On the other hand, our present data suggest that the parasympathetic activity is not yet significantly altered because of any change in the sensitivity of the reflex bradycardia. Furthermore, it is well established in the literature that the increase in sympathetic activity induces an increase in plasma leptin ${ }^{(9)}$, dietary intakes ${ }^{(44,45)}$, adipose tissue ${ }^{(46,47)}$ and $\mathrm{IR}^{(48,49)}$. In this way, in the present study, the increase in sympathetic activity must be involved in all cardio-metabolic alterations induced by the $\mathrm{H}$ diet of the progenitors that were transmitted to female and male $\mathrm{F} 1 \mathrm{H}$ and $\mathrm{F} 2 \mathrm{H}$ offspring. Again, the evaluation of the correlation between the plasma levels of leptin of $\mathrm{GOH}$ progenitor and F2H offspring showed a positive correlation with total cholesterol $(r$ 0.9684, effect size $=-1.48$; statistical power $=0.98)$, TAG ( $r$ 0.9857, effect size $=-3 \cdot 04$; statistical power $=1)$, glycaemia $(0.9034$, effect size $=-2.56$; statistical power $=1)$ and MAP $(r$ 0.9551, effect size $=-3 \cdot 11$; statistical power $=1)$ and negative correlation with sympathetic inhibition $(r-0.9321$, effect size $=4.79$; statistical power $=1)$.

In G1HF genitor, we observed less disturbances compared with G0HF genitor. The G1HF genitors showed similarity in the amount of $\mathrm{C}$ diet ingested, energy intake, adiposity index and HOMA- $\beta$ but increased plasma levels of leptin, total cholesterol, TAG and HOMA-IR. The less disturbances in G1HF are probably due to greater metabolic demand in the gestation and breast-feeding periods, inducing physiological adjustments ${ }^{(50)}$. However, these adjustments did not avoid the G1HF to transfer the disturbances totally to the $\mathrm{F} 2 \mathrm{H}$ offspring ${ }^{(50,51)}$.

The contribution of the father cannot be ignored in the transmission of metabolic dysfunction to the offspring ${ }^{(52,53)}$. In the present study, male genitors who received only the $\mathrm{H}$ diet for a short period of $10 \mathrm{~d}$ of mating showed increased body mass gain and MAP and HR compared with male genitors fed the C diet.

\section{Conclusion}

The present study shows that although the progenitors had a similarity in the energy intake, the $\mathrm{H}$ diet fed only during mating, gestation and breast-feeding increased arterial pressure, sympathetic activity, adiposity index, plasma levels of leptin and GJ. These progenitor disorders during pregnancy and breast-feeding induced increase in leptin levels and energy intake in offspring, even when they were fed only control diet and then triggering the occurrence of other disturbances characteristic of the MetS in $\mathrm{F} 1 \mathrm{H}$ and $\mathrm{F} 2 \mathrm{H}$ rats. Finally, our data reinforce the importance of balanced diet during pregnancy and breast-feeding for the generation of healthy F1 and F2 offspring.

\section{Acknowledgements}

This study was supported by the Universidade Federal de Ouro Preto (UFOP), Pró-Reitoria de Pós-Graduação (PROPP-UFOP), FAPEMIG (Fundação de Amparo à Pesquisa do Estado de Minas Gerais), CNPq (Conselho Nacional de Desenvolvimento Científico e Tecnológico). Claudiane Maria Barbosa received a Coordenação de Aperfeiçoamento de Pessoal de Nível Superior (CAPES) fellowship as doctoral student in the Programa de Pós-graduação-Ciências Biológicas, NUPEB, 
UFOP; CNPq (grant number universal 472497/2013-8); FAPEMIG (grant number APQ-01685-15).

A. C. A. conceived, designed the experiment, analysed the data and wrote the manuscript. C. M. B., V. P. F., M. A. B. and A. C. A. performed the experiments, analysed the data and wrote the manuscript. L. M. C analysed the data. All authors reviewed and approved the final version of the manuscript.

The authors declare that they have no conflicts of interest.

\section{Ethical Statement}

All procedures were performed in accordance with the Guidelines for Ethical Care of Experimental Animals and it was approved by the Animal Ethics Committee of the Federal University of Ouro Preto (protocol 2016/49) to not to cause suffering or pain to the animal. In experimental methods section, a specific ethics/approval number was inserted.

\section{Supplementary material}

For supplementary material referred to in this article, please visit https://doi.org/10.1017/S0007114519002708

\section{References}

1. Reaven GM (1988) Banting lecture 1988. Role of insulin resistance in human disease. Diabetes 37, 1595-1607.

2. Ginsberg HN \& Huang LS (2000) The insulin resistance syndrome: impact on lipoprotein metabolism and atherothrombosis. J Cardiovasc Risk 7, 325-331.

3. Barker DJ (1997) Maternal nutrition, fetal nutrition, and disease in later life. Nutrition 13, 807-813.

4. Volpato AM, Schultz A, Magalhaes-da-Costa E, et al. (2012) Maternal high-fat diet programs for metabolic disturbances in offspring despite leptin sensitivity. Neuroendocrinology $\mathbf{9 6}$, 272-284.

5. Williams L, Seki Y, Vuguin PM, et al. (2014) Animal models of in utero exposure to a high fat diet: a review. Biochim Biophys Acta 1842, 507-519.

6. Zhang Y, Proenca R, Maffei M, et al. (1994) Positional cloning of the mouse obese gene and its human homologue. Nature $\mathbf{3 7 2}$, 425-432.

7. Yu WH, Kimura M, Walczewska A, et al. (1997) Role of leptin in hypothalamic-pituitary function. Proc Natl Acad Sci U S A 94 , 1023-1028.

8. Otero M, Lago R, Gomez R, et al. (2006) Towards a proinflammatory and immunomodulatory emerging role of leptin. Rheumatology (Oxford) 45, 944-950.

9. Bornstein SR \& Torpy DJ (1998) Leptin and the reninangiotensin-aldosterone system. Hypertension 32, 376-377.

10. Dominici FP, Burghi V, Munoz MC, et al. (2014) Modulation of the action of insulin by angiotensin-(1-7). Clin Sci (Lond) 126, 613-630.

11. Julius $S$ \& Nesbitt $S$ (1996) Sympathetic overactivity in hypertension. A moving target. Am J Hypertens 9, 113S-120S.

12. de Castro UG, dos Santos RA, Silva ME, et al. (2013) Agedependent effect of high-fructose and high-fat diets on lipid metabolism and lipid accumulation in liver and kidney of rats. Lipids Health Dis 12, 136.

13. Iossa S, Lionetti L, Mollica MP, et al. (2003) Effect of high-fat feeding on metabolic efficiency and mitochondrial oxidative capacity in adult rats. Br J Nutr 90, 953-960.
14. Cunha TM, Lima WG, Silva ME, et al. (2013) The nonpeptide ANG-(1-7) mimic AVE 0991 attenuates cardiac remodeling and improves baroreflex sensitivity in renovascular hypertensive rats. Life Sci $\mathbf{9 2}$, 266-275.

15. Matthews DR, Hosker JP, Rudenski AS, et al. (1985) Homeostasis model assessment: insulin resistance and beta-cell function from fasting plasma glucose and insulin concentrations in man. Diabetologia 28, 412-419.

16. Dunn GA \& Bale TL (2011) Maternal high-fat diet effects on third-generation female body size via the paternal lineage. Endocrinology 152, 2228-2236.

17. Huang YH, Ye TT, Liu CX, et al. (2017) Maternal high-fat diet impairs glucose metabolism, beta-cell function and proliferation in the second generation of offspring rats. Nutr Metab 14, 67.

18. Vickers MH (2014) Developmental programming and transgenerational transmission of obesity. Ann Nutr Metab 64 , Suppl. 1, 26-34.

19. Campfield LA, Smith FJ, Guisez Y, et al. (1995) Recombinant mouse $\mathrm{OB}$ protein: evidence for a peripheral signal linking adiposity and central neural networks. Science 269, 546-549.

20. Kennedy GC (1953) The role of depot fat in the hypothalamic control of food intake in the rat. Proc R Soc Lond B Biol Sci $\mathbf{1 4 0}$, 578-596.

21. Ferezou-Viala J, Roy AF, Serougne C, et al. (2007) Long-term consequences of maternal high-fat feeding on hypothalamic leptin sensitivity and diet-induced obesity in the offspring. Am J Physiol Regul Integr Comp Physiol 293, R1056-R1062.

22. Morton GJ, Cummings DE, Baskin DG, et al. (2006) Central nervous system control of food intake and body weight. Nature 443, 289-295.

23. Schwartz MW, Woods SC, Porte D Jr, et al. (2000) Central nervous system control of food intake. Nature 404, 661-671.

24. Barbosa MA, Sá RG, De Castro UGM, et al. (2018) Physical training improves thermogenesis and insulin pathway, and induces remodeling in white and brown adipose tissues. $J$ Physiol Biochem 74, 441-454.

25. Townsend KL, Lorenzi MM \& Widmaier EP (2008) High-fat diet-induced changes in body mass and hypothalamic gene expression in wild-type and leptin-deficient mice. Endocrine 33, 176-188

26. Bouret SG (2009) Development of hypothalamic neural networks controlling appetite. Forum Nutr 63, 84-93.

27. Srinivasan M, Katewa SD, Palaniyappan A, et al. (2006) Maternal high-fat diet consumption results in fetal malprogramming predisposing to the onset of metabolic syndrome-like phenotype in adulthood. Am J Physiol Endocrinol Metab 291, E792-E799.

28. Ashino NG, Saito KN, Souza FD, et al. (2012) Maternal high-fat feeding through pregnancy and lactation predisposes mouse offspring to molecular insulin resistance and fatty liver. $J$ Nutr Biochem 23, 341-348.

29. Dunn GA \& Bale TL (2009) Maternal high-fat diet effects on third-generation female body size via the paternal lineage. Endocrinology 152, 2228-2236.

30. Masuyama H, Mitsui T, Eguchi T, et al. (2016) The effects of paternal high-fat diet exposure on offspring metabolism with epigenetic changes in the mouse adiponectin and leptin gene promoters. Am J Physiol Endocrinol Metab 311, E236-E245.

31. Tamashiro KL, Terrillion CE, Hyun J, et al. (2009) Prenatal stress or high-fat diet increases susceptibility to diet-induced obesity in rat offspring. Diabetes 58, 1116-1125.

32. Gniuli D, Calcagno A, Caristo ME, et al. (2008) Effects of high-fat diet exposure during fetal life on type 2 diabetes development in the progeny. J Lipid Res 49, 1936-1945. 
33. Desai M, Jellyman JK, Han G, et al. (2014) Maternal obesity and high-fat diet program offspring metabolic syndrome. Am J Obstet Gynecol 211, 237.e1-237.e13.

34. Aref AB, Ahmed OM, Ali LA, et al. (2013) Maternal rat diabetes mellitus deleteriously affects insulin sensitivity and Beta-cell function in the offspring. J Diabetes Res 2013, 429154.

35. Li P, Gong JX, Sun W, et al. (2015) Hexamethonium attenuates sympathetic activity and blood pressure in spontaneously hypertensive rats. Mol Med Rep 12, 7116-7122.

36. Gomes PM, Sa RWM, Aguiar GL, et al. (2017) Chronic high-sodium diet intake after weaning lead to neurogenic hypertension in adult Wistar rats. Sci Rep 7, 5655.

37. Santajuliana D, Hornfeldt BJ \& Osborn JW (1996) Use of ganglionic blockers to assess neurogenic pressor activity in conscious rats. J Pharmacol Toxicol Methods 35, 45-54.

38. Khan IY, Dekou V, Douglas G, et al. (2005) A high-fat diet during rat pregnancy or suckling induces cardiovascular dysfunction in adult offspring. Am J Physiol Regul Integr Comp Physiol 288, R127-R133.

39. Samuelsson AM, Matthews PA, Argenton M, et al. (2008) Diet-induced obesity in female mice leads to offspring hyperphagia, adiposity, hypertension, and insulin resistance: a novel murine model of developmental programming. Hypertension 51, 383-392.

40. Elahi MM, Cagampang FR, Mukhtar D, et al. (2009) Long-term maternal high-fat feeding from weaning through pregnancy and lactation predisposes offspring to hypertension, raised plasma lipids and fatty liver in mice. Br J Nutr $\mathbf{1 0 2}$, 514-519.

41. Zhang YP, Huo YL, Fang ZQ, et al. (2018) Maternal high-fat diet acts on the brain to induce baroreflex dysfunction and sensitization of angiotensin II-induced hypertension in adult offspring. Am J Physiol Heart Circ Physiol 314, H1061-H1069.

42. Dampney RA (1994) Functional organization of central pathways regulating the cardiovascular system. Physiol Rev $\mathbf{7 4}$, 323-364
43. Alzamora AC, Santos RA \& Campagnole-Santos MJ (2006) Baroreflex modulation by angiotensins at the rat rostral and caudal ventrolateral medulla. Am J Physiol Regul Integr Comp Physiol 290, R1027-R1034.

44. He W, Boesveldt S, Delplanque S, et al. (2017) Sensory-specific satiety: Added insights from autonomic nervous system responses and facial expressions. Physiol Behav 170, 12-18.

45. Guarino D, Nannipieri M, Iervasi G, et al. (2017) The role of the autonomic nervous system in the pathophysiology of obesity. Front Physiol 8, 665.

46. La Fountaine MF, Cirnigliaro CM, Kirshblum SC, et al. (2017) Effect of functional sympathetic nervous system impairment of the liver and abdominal visceral adipose tissue on circulating triglyceride-rich lipoproteins. PLOS ONE 12, e0173934.

47. Schumann U, Jenkinson CP, Alt A, et al. (2017) Sympathetic nervous system activity and anti-lipolytic response to iv-glucose load in subcutaneous adipose tissue of obese and obese type 2 diabetic subjects. PLOS ONE 12, e0173803.

48. Gastaldelli A, Gaggini M \& DeFronzo RA (2017) Role of adipose tissue insulin resistance in the natural history of type 2 diabetes: results from the San Antonio metabolism study. Diabetes $\mathbf{6 6}$, 815-822.

49. Ying W, Riopel M, Bandyopadhyay G, et al. (2017) Adipose tissue macrophage-derived exosomal miRNAs can modulate in vivo and in vitro insulin sensitivity. Cell 171, 372-384.e12.

50. King JC (2000) Physiology of pregnancy and nutrient metabolism. Am J Clin Nutr 71, 1218S-1225S.

51. Bell KJ, Hayen A, Irwig L, et al. (1995) When to remeasure cardiovascular risk in untreated people at low and intermediate risk: observational study. BMJ 346, f1895.

52. Rando OJ (2012) Daddy issues: paternal effects on phenotype. Cell 151, 702-708.

53. Fullston T, Palmer NO, Owens JA, et al. (2015) Diet-induced paternal obesity in the absence of diabetes diminishes the reproductive health of two subsequent generations of mice. Hum Reprod 27, 1391-1400. 